\title{
Comprehensive insurance protection of human capital in agriculture
}

\author{
Tatiana Odinokova*, Elena Dvoryadkina, and Natalia Istomina \\ Ural State University of Economics, Yekaterinburg, Russia
}

\begin{abstract}
Ensuring the development of agriculture as an important branch of the national economy and a resource that ensures national food security is traditionally in the interests of researchers. The study of the development of human capital in agriculture on the basis of a system of comprehensive insurance protection can be a relatively new vector of research. The article provides a brief description of the current state (development trends) of human capital in agriculture of the Russian Federation, the Russian practice of organizing insurance protection of human resources involved in agriculture, and identifies the need for comprehensive insurance protection. Conclusions on the need to embed a policy to ensure the development of insurance in rural areas into a unified state policy for the development of agriculture in combination with a policy for the development of state pension provision are presented.
\end{abstract}

\section{Introduction}

One of the serious problems of the world community, which does not lose its relevance, is the production of foodstuffs necessary for its life support. Moreover, this process must be continuous, since humanity can not only stop consuming, but must also increase food production, which is associated with the growth of needs and population on the planet. The effective organization of the agricultural complex: from growing plants and animals to providing this process with means and factors of production is known to be the basis for ensuring food security and independence of the country.

Human capital as a factor of production has the following features: it is the main value of society and is the main factor of economic growth; characterized by liquidity, service life, wear and tear and the need for investments, which provide a long-term and integrated economic and social effect. Human capital should be considered as the main link, on the state, success and intellectual and professional development potential of which not only the efficiency of the industry, but also the quality parameters of the products depends. The conducted research not only confirms the dependence of the economy and the agricultural sector on the accumulated human capital and the nature of its use, but also speaks of the need to develop a socio-economic policy aimed at consolidating and developing the achieved advantages [1].

\footnotetext{
* Corresponding author: tdo17@yandex.ru
} 
Human capital, as a category of scientific research, has been in the field of scientific thought of domestic and foreign scientists for a relatively long time. The modern theory of human capital was formulated in the works of Garry Becker (b. 1930). It was further developed in the works of T. Schultz, J. Ben-Porat, M. Blaug, W. Bowen, E. Denison, J. Kendrick, F. Machlup, G. Psakharopoulos, L. Thurow, B. Chiswick, E. Fromm, V.V. Bogatyreva, S.N. Gaponova, I.V. Gruzkov, D.V. Didenko, R.I. Kapelyushnikov, D.A. Kiryanov, V.A. Mau, N.V. Parushin, I.V. Sobolev and many others.

The role of human capital in relation to rural areas was considered by such scientists as E.V. Avdeev, M.V. Vatagina, A.F. Dorofeev, Yu.I. Koloskova, I.N. Merenkova, N.S. Paliy, O. Yu. Savenkov, V.S. Ternovykh, E.I. Tikhonov, E.V. Chernenko and others.

Currently, the governments of many countries, while developing policies to support the agricultural sector of the economy, are mainly focused on building human capital through approaches to economic and structural development, which emphasize education, training and financing of market infrastructure, access to land, capital, technology and manufacturing skills. Less attention is paid to the health, job quality and social infrastructure human capital needs of farm families and agricultural workers to support a more dynamic and sustainable agricultural economy $[2,3]$.

At the same time, human capital, including agricultural sector, having a value estimate, is a subject to the risk of depreciation, disability, increased costs of maintaining and restoring health, and early death. At the same time, the risks of human capital are often ignored by most enterprises, which negatively affects the achievement of financial stability of agricultural activities. Therefore, issues related to research, analysis and search for new approaches to the organization of human capital protection are extremely relevant. It is proposed to consider complex insurance coverage as one of the approaches. Expansion of insurance protection of human capital and mechanisms of its state regulation seems to be an extremely important and urgent task.

\section{Materials and methods}

To assess the current state (development trends) of human capital in agriculture of the Russian Federation and determine the need for comprehensive insurance protection, a study of indicators of the number of people employed in the industry, their share in the total number of people employed in the national economy of the Russian Federation, the qualitative composition of agricultural personnel, and real incomes of workers employed in agriculture (for the study, materials of official statistics on the listed indicators) will be carried out . As the main method in this part of the study, the method of economic analysis, based on the evolutionary methodology of scientific knowledge, will be used. Based on this part of the study, it is proposed to assess the negative impact of existing trends on the rural population of Russia. To substantiate the need for comprehensive insurance protection of human capital in the agricultural sector, it is planned to use the induction method as the basic method, with the help of which it is proposed to move, from the systematization of private factors (characterizing the state of agriculture as a sector of the economy and the specifics of the risks of human capital in agriculture) to generalized conclusions on the significance and content of comprehensive protection of human capital based on the insurance principles.

Generalized data of the state regulator of the insurance sector, as well as the results of the authors' own research will become the materials for the study of the Russian practice of organizing insurance protection of human resources involved in agriculture. The method of comparative analysis will be used as the main method. 


\section{Results and discussion}

The current state of human capital in the Russian agricultural sector reflects the state of affairs and the main problems of the industry. The human capital of this industry is characterized by the following significant development trends:

- firstly, a decrease in the absolute number of people employed in agriculture, and, accordingly, their share in the structure of the total number of people employed in the economy, due to an increase in the rate of rural-urban migration, a decline of interest among young people in agricultural professions, and a deterioration in the demographic situation of the rural population;

- $\quad$ secondly, the deterioration of the qualitative composition of agricultural personnel, due to the aggravation of social problems, unfavorable working conditions, the departure and replacement of specialists, managers and qualified personnel, leading as a consequence to the emergence of other unfavorable trends, such as aging of personnel, a decline in prestige for youth of blue-collar occupations in agriculture [4];

- thirdly, the decline in the level of employment in agriculture led to structural sectoral mobility and caused the development of the informal sector, which employs a third of the rural population (in 2017 - 38.5\%, in 2018 - 39.5\%, in 2019 - 40\% ) [5];

- fourthly, getting an average monthly wage in agriculture is associated with a greater number of hours worked than in the economy as a whole: for example, the actual hours worked per year at workplaces and jobs in 2017 amounted to 20,515, in $2018-20,149$, in 2019 - 20,311 million man-hours;

- fifthly, a decrease in the real incomes of employees: for example, since 2012, there has been a tendency for a decrease in the number of employees with overdue wage arrears, as well as the total amount of arrears (from 176.4 million rubles at the beginning of 2012 to 133,0 million rubles at the beginning of 2019). At the same time, in terms of one employee, the amount of debt increased from 14.5 thousand to 52.8 thousand rubles for the same period (Fig. 1).

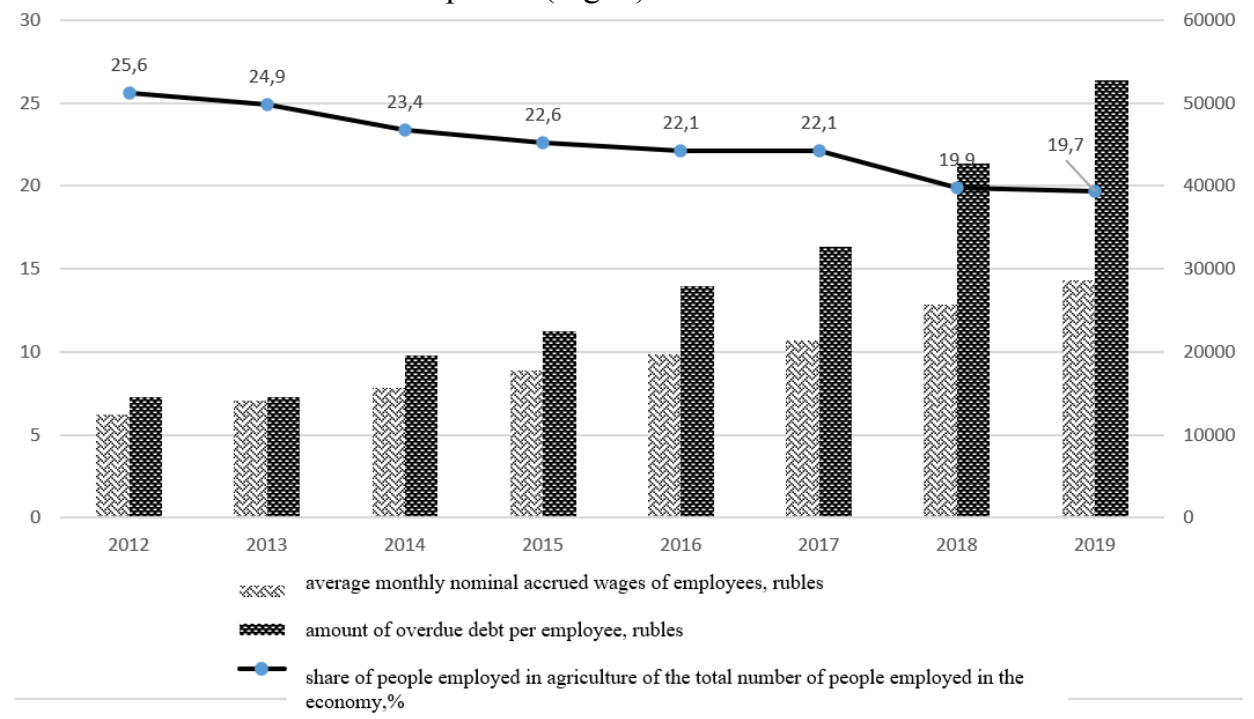

Source: [5]

Fig. 1. Dynamics of the average annual number and structure of the employed population in the agricultural sector of Russia (thousand people \%) 
A decrease in the average annual employment of the population, a decrease in income and an increase in overdue wage arrears, the lack of prospects for improving working conditions have led to a deterioration in the quality of life, and, as a consequence, to a depopulation of the rural population and deformation of its sex and age structure. Almost each of these factors is a consequence and prerequisite of not one, but a number of limitations. For example, on the one hand, a low level of labor productivity predetermines a low level of income, being, at the same time, its consequence, since it is largely due to the low development of the system of general and vocational education, which, in turn, cannot develop due to a low level of income. On the other hand, the lower the income level is, the lower the quality of life is and hence the risks of morbidity, death at employable age, qualitative and quantitative indicators of the reproduction of human capital, disability, decrease (shortfall) in income, expenses for health recovery.

The specifics of human capital risks in agriculture are influenced by such factors as territorial remoteness and lack of transport accessibility, lack of savings among the rural population, which they could use for timely and highly qualified consultation and medical care, low qualification of rural medical personnel, lack of pharmacies and low rates of development of telemedicine, the presence of a large list of settlements on the territory of which there is no access to the Internet. High risks for national human capital are created not only by demographic trends (aging of the population and high mortality in the working age), but also by extremely low efficiency in the use of available labor resources [6]. All these factors determine the need to develop measures for the comprehensive protection of human capital in the agricultural sector of Russia.

Currently, both preventive measures and state measures of social support, including social insurance, are used in the field of human capital management in the agricultural sector in the Russian Federation. Preventive measures include: managing the behavior and thinking of workers, organizing their professional training in order to improve the skills of the workforce and improve individual performance, increasing financial literacy in order to manage their resources better, conducting preventive medical examinations in order to identify deviations in the health of workers and prevent disability, and taking into account the needs of workers and their families for personal insurance so that they do not have to worry about medical expenses or treatment in the future. Social support is represented by a broader system of measures: programs to promote an increase in the birth rate, programs to support large families, a program to support low-income families, a program to improve the quality of housing conditions in rural areas, a special program for young professionals whose profession is closely related to agriculture, etc. ., within the framework of which the population has the right to social benefits, tax benefits, material assistance and compensation for the purchase of medicines, subsidies issued for the development of farms, discounts and subsidies for the payment of utilities, subsidies for gasification to pensioners, the provision of free medicines and etc. Within the framework of social insurance, the following support measures are being implemented: the provision of pension allowances, a reduction in the working week for working women in the village, an increase in the duration of the main vacation to 28 , and to 42 calendar days for working pensioners, providing early retirement pension, etc.

As the analysis of Russian practice shows, the organization of social protection of human resources involved in agriculture is limited only by state measures: social support and social insurance. At the same time, due to objective factors, employees of this industry cannot provide additional protection against possible risks as concerns their individual personal insurance on their own. In addition, agricultural enterprises, due to state regulation in the field of pricing, high dependence on intermediaries, monopolists-processors and trade, as well as seasonality and a long production cycle, do not receive high revenue figures and, as a result, are unable to implement corporate employee insurance programs. ... 
A feature of the Russian Federation is the fact that the state social insurance covers almost the entire Russian population, and is not tied exclusively to its employment, which imposes certain obligations on the state and leads to an increase in the costs of maintaining this system at an acceptable level [7]. As a result, public social insurance, which includes compulsory pension, health and disability insurance due to illness, injury and maternity, is the main and often the only source of financing the risks of human capital in the agricultural sector.

According to the authors, comprehensive protection of human capital in agriculture should be realized on the basis of an insurance nature. A comprehensive insurance organization for the protection of the population is an optimal system, provided that it includes the following levels: (1) state social insurance and pensions under the same conditions for receiving benefits and pensions; (2) collective insurance of employees at the expense of enterprises (or trade unions); (3) conclusion of an individual insurance contract by the employee himself. Here, one of the consequences of market relations, obviously, will be an increase in the role of risky types of insurance with a slight decrease (but not abolition) of savings types [8].

Development and implementation of comprehensive insurance protection of human capital in the agricultural sector will allow:

1) to improve the financial and social protection of agricultural workers;

2) to reduce the level of social stratification of the rural and urban population.

3 ) to increase the role of preventive measures, which will objectively have to be implemented by agricultural producers in order to reduce the cost of insurance fees.

4) to increase the corporate social responsibility of agricultural enterprises.

5) to form an effective mechanism based on the relationship between public, private corporate and individual insurance.

6) to reduce budget expenditures by redistributing the load among those interested in the development of human capital in agriculture.

7) to increase the efficiency of the organization of social protection based on insurance principles.

8) to ensure the availability of medical services for agricultural workers [9];

9) to attract highly qualified personnel capable of solving highly complex tasks [10].

\section{Conclusions}

The formation of a set of factors contributing to the development of agriculture (one of which is comprehensive insurance protection of human capital) corresponds to a more global goal - ensuring national food security. In the context of restrictive (sanctions) measures, reducing food imports, promoting food security is a key element of the state policy of the Russian Federation.

Thus, considering the comprehensive insurance protection of human capital in agriculture in the context of the state policy of ensuring food security, it is necessary to especially emphasize the importance of developing a unified state approach to the development of insurance in rural regions of the country, as well as ensuring appropriate financial support for both the rural population and insurance organizations. working in rural areas in order to create conditions for the implementation of insurance protection programs for residents of rural areas and agricultural enterprises in combination with state social insurance and pensions.

The fundamental limitation that prevents the formation of comprehensive insurance protection for human capital in agricultural areas is the low level of income of the population, which does not allow citizens to divert resources from their current needs for the costs associated with the payment of insurance premiums. If this trend persists for a 
long time, the risk of curtailing economic and other types of activity in rural settlements increases, which in the case of an initially lower quality of social infrastructure, fewer educational opportunities, etc. will have an extremely detrimental effect on the human capital of initially individual rural areas, and then on the human capital in agriculture as a whole.

Therefore, the state policy for the development of insurance in rural areas cannot be considered and implemented in isolation from the state policy for the development of agriculture in agricultural areas. A comprehensive state policy should help to increase the attractiveness of labor in agriculture, stimulate the inflow of investments (including with direct financing of investment projects from the state budget), and ensure the creation of the necessary infrastructure for the population. If this vector of state policy is maintained for a long time, conditions for the long-term development of human capital will be formed and hence the programs for the development of insurance will have a more predictable positive result. In particular, the population of rural areas will be more focused on concluding individual insurance contracts.

It is important to understand that the profitability of agriculture tends to be lower than the profitability of industry or trade. Therefore, enterprises in the agricultural sector, as well as residents of rural areas, find it difficult to find funds for collective insurance of workers, which is also an element of comprehensive insurance protection for human capital in agriculture. At the same time, the level of risks that could be included in such collective insurance contracts, due to the initial riskiness of agricultural activities, is quite high. Therefore, considering the issue of incentivizing agricultural enterprises to conclude insurance contracts for their employees, it is rational to include in the agenda issues on the development of reinsurance or co-insurance, as well as state co-financing of expenses related to the payment of insurance premiums.

Within the framework of comprehensive insurance protection of human capital, the role of the state can also be associated with resolving issues of additional pension and health insurance for employees of agricultural enterprises or farms, which will help to attract the population to rural areas, subject to appropriate attention to the needs of human capital related to the quality of jobs., the necessary social infrastructure, etc. Practice shows that state and local authorities are not always sufficiently informed about the resources of the territory, including the resources of an implicit nature, such as, for example, human resources [11]. Therefore, special attention should be paid to the "inventory" of available resources. In the process of working out solutions for the implementation of comprehensive insurance protection of human capital in the agricultural sector, it is necessary to control the emergence of possible restrictions, including: the growth of requirements for insurance institutions; increasing the burden on agricultural producers; increasing the burden on state authorities represented by the Ministry of Agriculture in connection with the need to monitor and control the implementation of the developed measures to support, develop and protect human resources involved in this industry.

\section{References}

1. A.L. Pustuev, O.S. Gorbunov, V.I. Nabokov, S.V. Petryakova, V.V. Kalitskaya, I.M. Perminova, AVU, 4(158) (2017)

2. G.W. Gillespie, S.E. Johnson, J. Agric. Food Syst. Dev community, 1(1), 31 (2010)

3. S. Sureshwaran et al., Choices, 26, 2 (2011)

4. N.G. Vozhdaeva, I.V. Volkov, Vestnik NGIEI, 5(48) (2015)

5. On the state of rural areas in the Russian Federation in 2018, Annual report on the results of monitoring, 6, 224 (2020) https://mcx.gov.ru/ 
6. N.F. Chelukhina, Funds, money, investments, 3(59), 16 (2016)

7. T.D. Odinokova, N.A. Istomina, AEBMR, 138, 720 (2020)

8. E.V. Kolomin, Reflections on insurance: scientific publication, Insurance Review, 378 (2006)

9. S. Inwood, Journal of Rural Studies, 54, 1 (2017)

10. E.V. Popov, M.V. Vlasov, A. Yu. Shishkina, Journal of New Economy, 20(2), 71 (2019)

11. E.B. Dvoryadkina, E.A. Belousov, Manager, 11(3), 2 (2020) 